\title{
Safety and Efficacy of Imiquimod in the Treatment of Infantile Hemangioma; a Systematic Review and Meta-Analysis
}

\author{
Abdullah Alakeel ${ }^{\star, \dagger}$ \\ College of medicine, University medical city, King Saud University, Riyadh, Saudi Arabia \\ QDOI: https://doi.org/10.15520/jcmro.v3i03.270
}

Accepted 29-03-2020; Received 01-03-2020; Publish Online 30-03-2020

\author{
Reviewed By: \\ Dr. K. Akarowhe \\ Department: \\ Reviewer/CMRO
}

\begin{abstract}
Objective: To study the safety and efficacy of imiquimod in the treatment of infantile hemangioma $(\mathrm{IH})$.

Method: Systematic search was conducted in nine electronic databases for selecting relevant articles reporting the safety and efficacy of imiquimod as a therapeutic agent for treatment of IH. Meta-analysis was used to pool the results.

Results: Of total 180 records screened, we included 9 studies for this systematic review and meta-analysis. About one-fifth of the patients $(20.9 \%)$ have showed clinical resolution with $95 \%$ confidence interval (CI) of $11.8 \%$ to $34.1 \%$. Regarding IH type, superficial type showed the highest rates of both clinical resolution and excellent response rates with $31.2 \%(95 \% \mathrm{CI}=16.6 \%$ to $50.8 \%)$ and $26.5 \%(95 \% \mathrm{CI}=11.6 \%$ to $49.6 \%$ ), respectively. A relatively high prevalence of any side effects with $63.1 \%$ $(95 \% \mathrm{CI}=47.6 \%$ to $76.3 \%)$ has been reported. The highest reported side effect was crustation $(44.1 \% ; 95 \% \mathrm{CI}=27.8 \%$ to $61.8 \%)$.

Conclusion: Imiquimod is effective in the treatment of superficial IH and it is associated with local side effects.
\end{abstract}

Key words: Imiquimod-Infantile Hemangioma-Systematic Review

\section{INTRODUCTION:}

The two major types of vascular lesions in infants are; tumors and vascular malformations [1]. The most common tumors in infancy, of a vascular origin, are hemangiomas. The exact incidence may not be known; however, the reported incidence is ranging from $4 \%$ to $10 \%$ of the Caucasian infants [2-5] Most of the hemangiomas are occurring in a sporadic way and in some cases, the autosomal dominant pattern of familial transmission; has been also reported [6]. In a large series of 136 families having established infantile hemangiomas (IHs), about one-third of the patients have an associated family history; mostly among first-degree relatives [7]. Noteworthy, IHs are three times more common among females (as compared to males) [810] and in non-Hispanic white races (as compared to other ethnic groups) $[4,10,11]$. The most commonly reported risk factor is the low birth weight; hence, the preterm infants

\footnotetext{
* Corresponding author.

$\dagger$ Email: dr_alakeel@hotmail.com
}

have an increased incidence of hemangiomas [10]

The growth of IHs has a characteristic life cycle of two dynamic phases; proliferation and involution [12-14]. A proliferation phase started at the early infancy, followed by an intermediate "plateau" phase during the mid-to-late infancy then the involution phase by the first year of life [12-14]. Morphologically, IHs can be classified into three types; superficial, deep and mixed $[12,15]$. The most common presentation is the superficial type which consists of a bright red lesion (a nodule, papule or plaque) raised above the skin; which is so-called a "strawberry" or "capillary" hemangioma [16, 17]. The deep/subcutaneous type is a less common presentation with a typically raised colored skin nodule (a bluish hue) with/without a telangiectatic patch; which is so-called a "cavernous" hemangioma [16] . The mixed/combined IHs are the least common with having the features of both superficial and deep hemangiomas [16]. It should be noted that most of the IHs are not clinically evident at birth and takes up to months to be noted $[9,18]$ 
Despite the fact that IHs are benign and self-limited in nature, they can cause serious complications such as ulceration or a permanent skin disfigurement [9, 12, 19]. Furthermore, they may compromise the functions of a vital organ or develop life-threatening visceral hemangiomas [9, 12, 19]. The approach to the treatment of hemangiomas should be individualized, based upon the size of the lesion, morphology, location, presence or possibility of complications, the potential for scarring or disfigurement, the age of the patient, and the rate of growth or involution at the time of evaluation $[16,20]$. The topical treatment is used mainly for uncomplicated IHs which includes topical beta-blockers, corticosteroids, and imiquimod [21-24]. Imiquimod is a topical immune response modifier with antiangiogenic and proapoptotic properties [24]. The current evidence about the efficacy of imiquimod for the treatment IHs is conflicting [25-30]. In this study, we aim to summarize the available evidence in this regard with stressing on the possible side effects as well.

\section{METHOD:}

\section{Search strategy and study selection:}

The study process was conducted following the accepted methodology recommendations of the PRISMA checklist for systematic review and meta-analysis where registration of the protocol is not mandated [31]. We conducted a systematic electronic database search for suitable studies from inception till $10^{\text {th }}$ December 2019 in nine databases including Google Scholar, System for Information on Grey Literature in Europe (SIGLE), Scopus, Web of Science (ISI), PubMed, Virtual Health Library (VHL), Clinical trials.gov, metaRegister of Controlled Trials (mRCT) and The WHO International Clinical Trials Registry Platform (ICTRP) databases using the following search term: (imiquimod and infantile hemangioma). We conducted manual search of references in our included papers for collecting missed relevant studies [32]. We included all relevant original publications reporting saftety and efficacy of treatment of infantile hemangioma with imiquimod. There were no restrictions on study design, country, language or publication date. Papers were excluded if there were one of the following exclusion criteria: i) in vitro or animal studies; ii) data duplication, overlapping or unreliably extracted or incomplete data; iii) abstract only articles, reviews, thesis, books, conference papers or articles without available full texts (conferences, editorials, author response, letters, and comments. Three independent reviewers screened title and abstract for selecting eligible papers. Further full text screening was performed to ensure the inclusion of relevant papers in our systematic review. Any disagreement was done by discussion and consulting the senior member when necessary.

Data extraction :

The data extraction form was developed by two authors, using a Microsoft Excel file. Three reviewers independently extracted data from included studies using the excel sheet. Data checking was performed through a fourth reviewer. All the disagreements and discrepancies were resolved by discussion and consultation with a senior member when necessary.

\section{Quality assessment :}

Three independent reviewers evaluated the risk of bias in included studies. The National Institutes of Health (NIH) quality assessment tool was used to assess the quality of each included studies [33]. Quality assessment of each study was obtained through a scoring system including 14 questions. The criterion was judged as following; a score of 13 to 14 was good, 9 to 12 was fair, and studies scoring below 9 are considered of poor quality for cohort studies [34]. Any discrepancy between the reviewers was solved by discussion.

\section{Statistical analysis:}

All data were analyzed using $\mathrm{R}$ software version 3.6.1 [35]. Using the "meta" package, different clinical response rates and the prevalence of side effects; have been calculated [36]. The corresponding 95\% confidence intervals (CI) of pooled effect size were calculated using a random-effects due to the presence of heterogeneity. Heterogeneity was assessed with $\mathrm{Q}$ statistics and $\mathrm{I}^{2}$ test considering it significant with $\mathrm{I}^{2}$ value $>50 \%$ or $\mathrm{P}$-value $<0.05$ [37]. Publication bias could not be assessed using Egger's regression test due to the small number of included studies (less than 10) [38, 39] .

\section{RESULTS:}

\section{Study characteristics:}

Our systematic search yielded 232 reports. By using endnote software, we excluded 52 duplicates. Title and abstract screening resulted in exclusion of 153 reports inclusion of 27 reports for further full text screening. Seven articles were eligible for inclusion after full text screening. Additional two papers were added after performing manual search. Finally, we included 9 studies for this systematic review [4048]Figure 1

There were three retrospective cohorts and five prospective ones and one non-randomized clinical trial Table 1 . The sample size was 253 patients ranged from 9 to 68 patients. Regarding IH type, 164 patients had superficial IH, 40 had mixed IH, 14 had deep IH and the type was not reported in 25 patients. All studies were of fair criterion.

\section{Clinical response rates}

Five studies with 158 patients were assessed for clinical resolution rates, following the use of imiquimod. In the same context, five studies (155 patients), seven studies (180 patients), six studies (171 patients), and five studies (146 patients) have assessed different response degrees of excellent (100 to $75 \%$ ), moderate (50 to $75 \%$ ), minimal (25 to $50 \%$ ), and poor response and /or failure (0 to $25 \%$ ), respectively.

About one-fifth of the patients $(20.9 \%)$ have showed clinical resolution with $95 \%$ CI of $11.8 \%$ to $34.1 \%$ Figure 2 . Moreover, the reported rates of excellent and moderate responses were $18.3 \%$ (95\% CI $=12.8 \%$ to $25.4 \%$ ) and $20.2 \%$ (95\% CI $=12.6 \%$ to $30.8 \%)$, respectively. Nevertheless, the reported minimal and poor/failure rate were considerably high with $29.2 \%$ (95\% CI= $15.9 \%$ to $47.4 \%)$ and $34.3 \%(95 \%$ $\mathrm{CI}=26.9 \%$ to $42.5 \%$ ), respectively Figure 2 . 

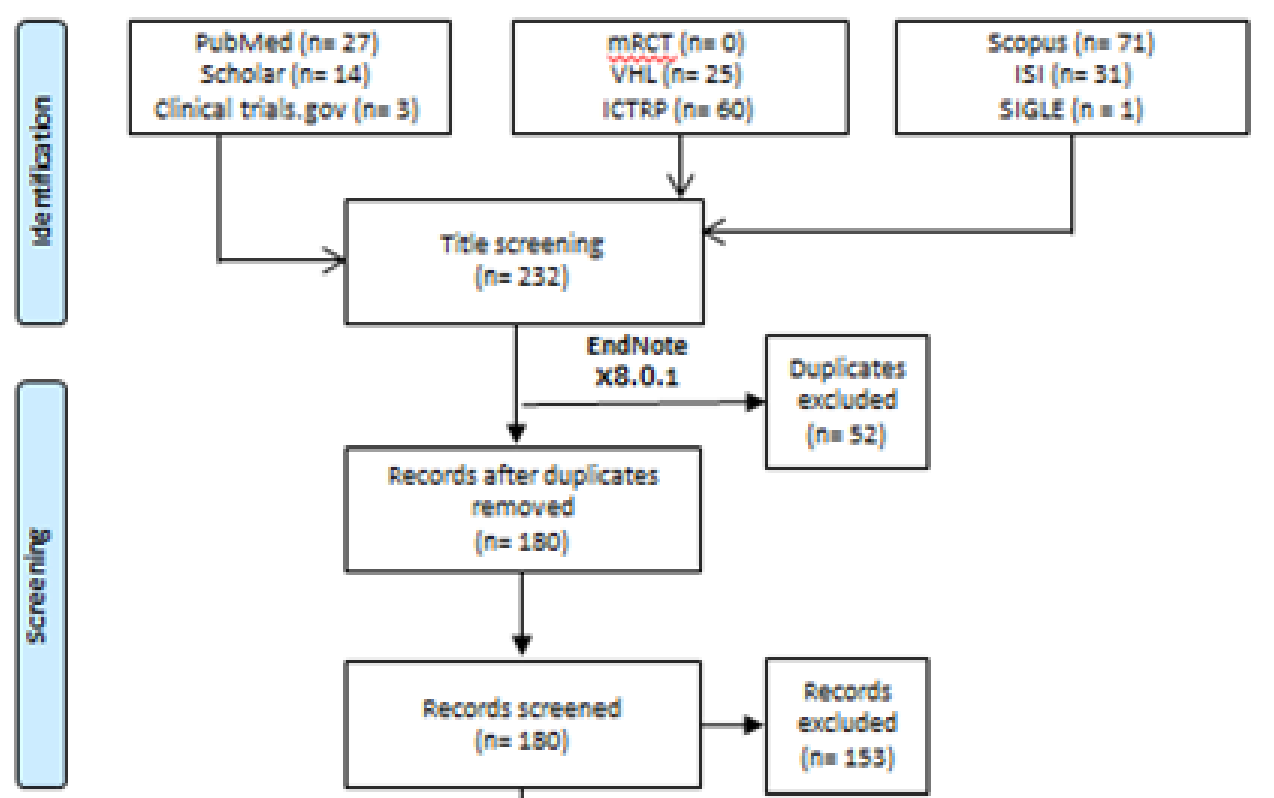

Records after duplicates

removed

$(n=180)$
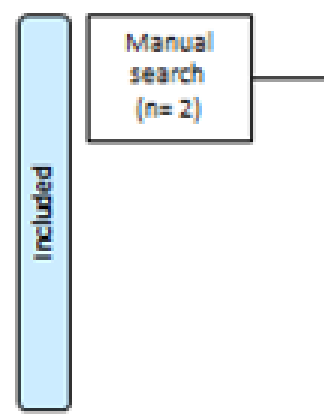

Qualtative synthesis $(n=9)$

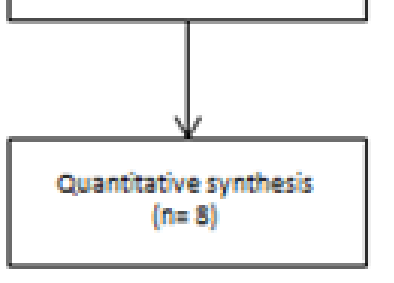

- Includes Imelevant articles, No reliable or overlapped data.

- Includes Conference papers, reviews, books, editorials, letters, oral presentation, correspondence, communications and posters.

Figure 1. Flow chart of theprocess of the review

Table 1. Studycharacteristic table

\begin{tabular}{|c|c|c|c|c|c|c|c|c|}
\hline \multirow[t]{2}{*}{ Reference ID } & \multirow{2}{*}{$\begin{array}{l}\text { Study } \\
\text { design }\end{array}$} & \multirow{2}{*}{$\begin{array}{l}\text { Sample } \\
\text { size }\end{array}$} & \multirow{2}{*}{$\begin{array}{l}\text { Age in months } \\
\text { (mean (SD)) }\end{array}$} & \multirow{2}{*}{$\begin{array}{c}\text { Male } \\
\text { (event) }\end{array}$} & \multicolumn{3}{|c|}{ Type of IH (Event) } & \multirow[t]{2}{*}{ QA } \\
\hline & & & & & Superficial & Mixed & Deep & \\
\hline $\mathrm{Ho} / 2007 /$ Canada & $\mathrm{RC}$ & 18 & $18 * \#$ & 2 & 12 & 3 & 3 & Fair \\
\hline Jiang/2011/China & PC & 44 & 3.4 & NR & 31 & 13 & - & Fair \\
\hline $\mathrm{Mao} / 2012 /$ China & $\mathrm{RC}$ & 19 & NR & 5 & 12 & 7 & - & Fair \\
\hline McCuaig/2009/Canada & PC & 16 & $4.1(1.9)$ & 5 & 10 & 5 & 1 & Fair \\
\hline Qiu/2013/China & $\mathrm{RC}$ & 9 & $3.3(1.7)$ & 5 & 9 & - & - & Fair \\
\hline Seirafi/2012/Iran & PC & 15 & $9.1(6.3)$ & 5 & NR & NR & NR & Fair \\
\hline Welsh/2004/USA & $\mathrm{PC}$ & 10 & $3-7^{* *}$ & 4 & 10 & - & - & Fair \\
\hline Guo/2009/China & PC & 68 & $14^{*}$ & 18 & 36 & 12 & 10 & Fair \\
\hline $\mathrm{Hu} / 2014 /$ China *** & Non-RCT & 54 & $14.6^{* \#}$ & 26 & 54 & - & - & \\
\hline
\end{tabular}




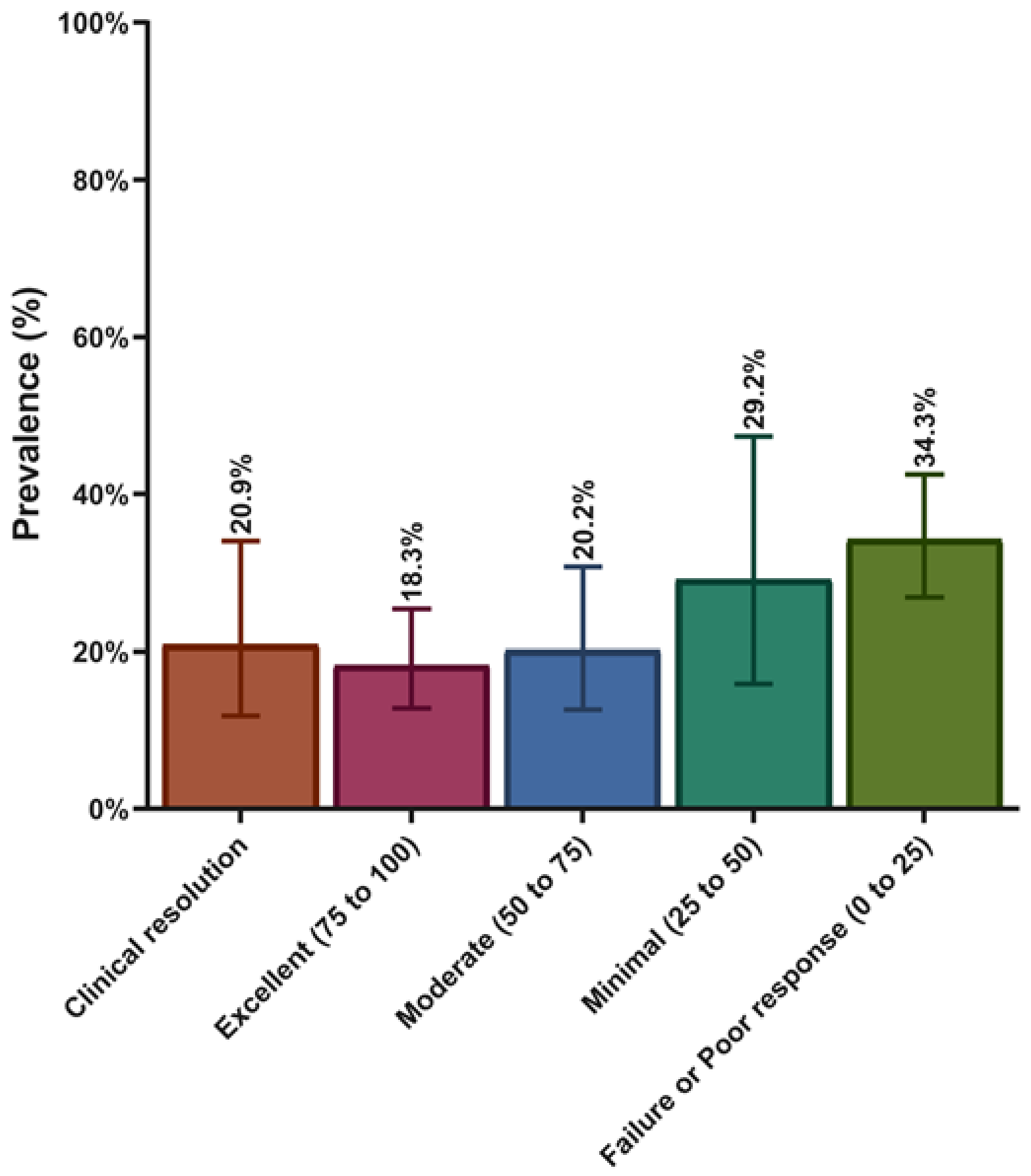

Figure 2. Showingclinical response of infantile hemangioma after treatment of imiquimod 
On the comparison of different types of hemangioma, superficial type showed the highest rates of both clinical resolution and excellent response rates with $31.2 \%(95 \% \mathrm{CI}=$ $16.6 \%$ to $50.8 \%)$ and $26.5 \%(95 \% \mathrm{CI}=11.6 \%$ to $49.6 \%)$, respectively. In contrast, the worst response rates were reported in patients with deep hemangiomas where $66.7 \%$ $(95 \% \mathrm{CI}=15.4 \%$ to $95.7 \%)$ of the cases showing poor response or treatment failure Figure 3.

\section{Prevalence of side effects}

Three studies with 86 patients has reported the rates of different side effects. A relatively high prevalence of any side effects with $63.1 \%(95 \% \mathrm{CI}=47.6 \%$ to $76.3 \%)$ has been reported. The highest reported side effects were crustation $(44.1 \%$; $95 \%$ CI $=27.8 \%$ to $61.8 \%)$, erythema/edema $(34.5 \% ; 95 \% \mathrm{CI}=17.5 \%$ to $56.6 \%)$, and erosion/light crustation $(31.6 \% ; 95 \% \mathrm{CI}=14.9 \%$ to $54.8 \%)$. In contrast, the lowest reported side effects were nausea $(5.3 \% ; 95 \% \mathrm{CI}=0.7 \%$ to $29.4 \%$ ), inflammation $(5.6 \% ; 95 \% \mathrm{CI}=0.8 \%$ to $30.7 \%)$, and peeling $(6.8 \% ; 95 \% \mathrm{CI}=2.2 \%$ to $19.1 \%)$, respectively Figure 4 .

\section{DISCUSSION:}

IH is a common benign tumor in infancy affecting approximately $4-10 \%$ [49]. Mainly, IH requires no treatment as the major growth of $\mathrm{IH}$ occurs at 5 months with subsequent remission with the infant growth [50]. However, if IH comprises a variable complications such as ulceration, interference with vision, airway and hearing; treatment is mandated [51]. Moreover, cosmetic appearance of affected cases constitutes an important indication for treatment due to the interference of the psychological life of the child compared to healthy peers [52].

Different therapeutic modalities have been developed for the treatment of IH. Historically, the treatment of IH consists of corticosteroids, surgical excision and laser therapy [53-55]. Due to the associated side effects of long term treatment with corticosteroids in addition to the contraindication of surgery in some children; emergence of new drugs has become the primary concern among physicians [56]. Imiquimod is an immune-modulator drug that promotes the release of cytokines and tumor necrosis factor (TNF) directly and IFN gamma (IFN-) which in part decrease the blood supply of IH in addition to limitation of their proliferation [57, 58].

In our study, the clinical resolution of IH treated with imiquimod was successful in one fifth of patients. In parallel with Ho et al [10] , study that reported a successful clinical resolution rate in $22 \%$ of the population. Additionally, Guo et al [47], indicated that a quarter of patients experienced clinical resolution of IH. On the contrary, clinical resolution was demonstrated as 7 and $16 \%$ for Jiang et al [41] , and Mao et al [42], respectively.

Subgroup analysis based upon IH type, showed that imiquimod is beneficial in promoting clinical resolution in nearly one third of superficial hemangioma patients in addition to providing a remarkable excellent and moderate improvement in approximately $25 \%$ and $20 \%$ of superficial IH patients, respectively. However, the drug had a minimal improvement and /or failure rates in nearly two thirds of deep type and half of mixed type of IH patients. The high efficacy in treating superficial but not deep and mixed type of IH can be explained through the topical action of the drug which may fail dramatically in reaching large parts of the deep and the mixed types of IH [41].

Despite being an efficient drug for treating superficial $\mathrm{IH}$, various side effects had been reported through different studies ranging from local to systemic negative consequences $[42,46]$. In our study, the prevalence of patients receiving imiquimod- that experienced side effects was $63 \%$. Our results was nearly similar to Guo et al [47], where $59 \%$ of patients revealed one or more local side effects. However, 14 out of 16 patients in McCuaig et al [43], reported local skin reactions.

The side effects were mainly local in origin; however, two patients experienced fever, 1 reported nausea and vomiting affected one participant, Mao et al [42]. Various local side effects were demonstrated by many studies such as ulceration, crustation, erythema, itching and sacring [41, 44, 46, 47]. The most common presented side effects in our study were crustation and erythema and edema revealing percentages of $44 \%$ and $34 \%$, respectively. Similar observation was indicated by Jiang et al [41] in which $55 \%$ of $\mathrm{IH}$ patients developed crustation, out of these two thirds were of superficial type and the other third was of mixed type. Furthermore, erythema and oedema was the most common negative conseqences associated with treatment of imiquimod with a percentage of $30 \%$ [47].

\section{Limitations:}

Our study should be interpreted with several limitations. Firstly, inclusion of retrospective cohort studies therefore selection bias could not be avoided. Secondly, the difference in age, sex and duration of the drug application may influence the reported efficacy and side effects as well; therefore, more studies are needed to address this issue.

\section{CONCLUSION:}

Imiquimod is effective in the treatment of superficial but not deep and mixed types of $\mathrm{IH}$ with moderate range of local side effects.

Funding: None

Declaration of Conflicting Interests: None

\section{REFERENCES}

[1] Chang LC, Haggstrom AN, Drolet BA, Baselga E, Chamlin SL, Garzon MC, et al. Growth Characteristics of Infantile Hemangiomas: Implications for Management. PEDIATRICS. 2008;122(2):360-367. Available from: https: //dx.doi.org/10.1542/peds.2007-2767.

[2] Darrow DH, Greene AK, Mancini AJ, Nopper AJ, O S, H O. Section On Dermatology, S. Neck, et al. Diagnosis and Management of Infantile Hemangioma. Pediatrics. 2015;136(4):1060-104. 


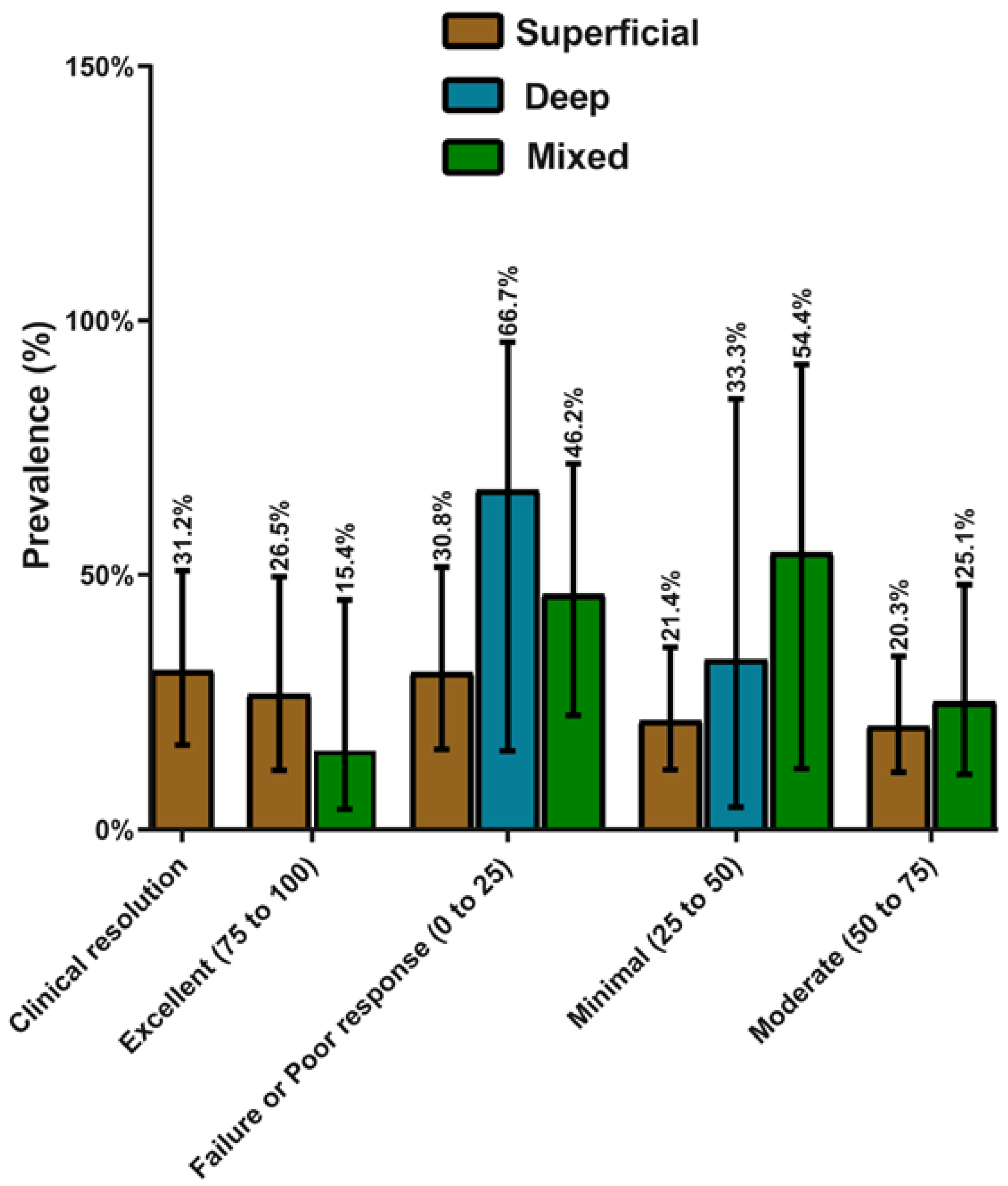

Figure 3. Showingsubgroup analysis of infantile hemangioma after treatment of imiquimod 


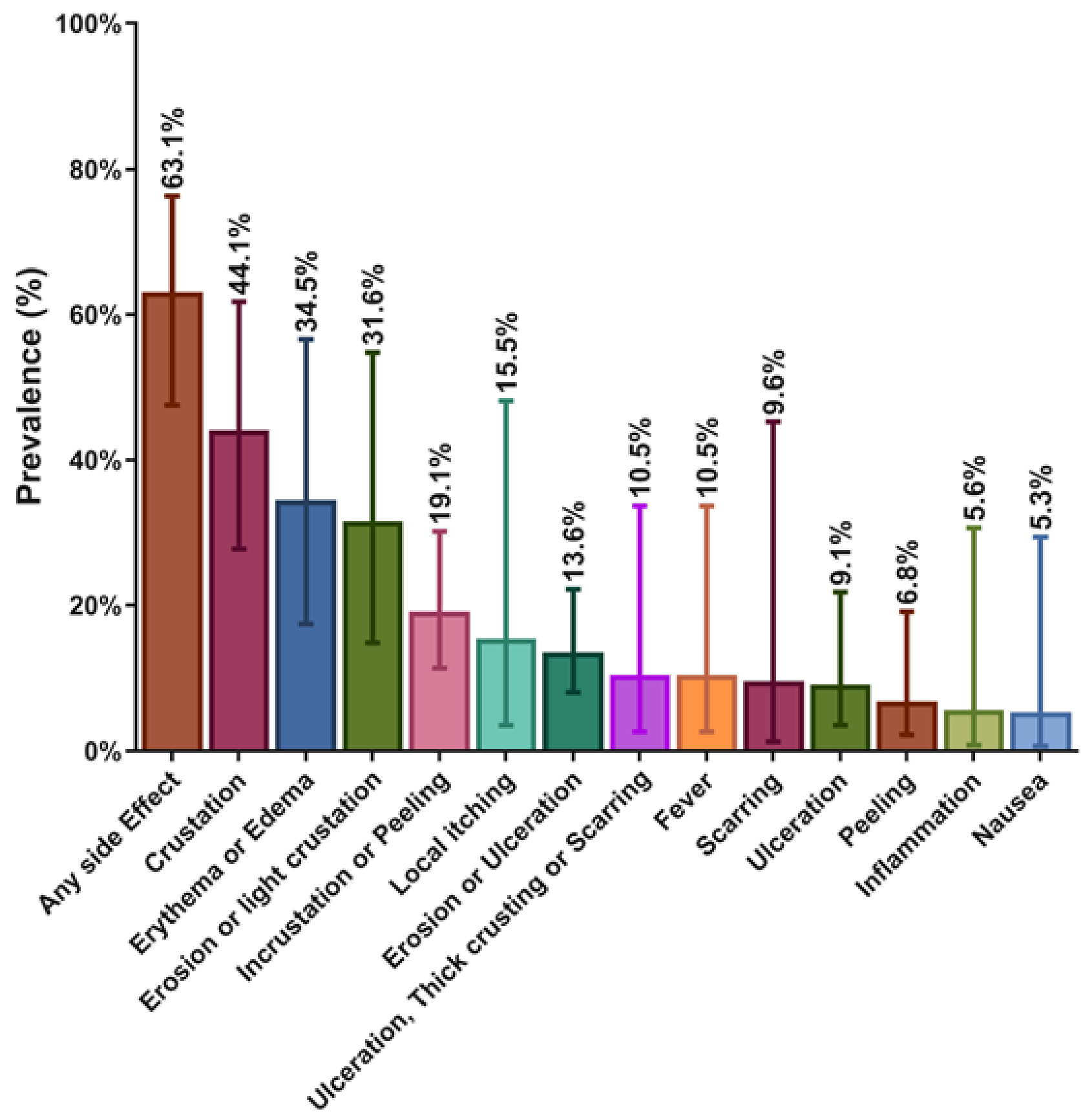

Figure 4. Showing theprevalence of side effects after treatment of infantile hemangioma with imiquimod 
[3] Senchak AJ, Dann M, Cable B, Bessinger G. Successful treatment of cutaneous hemangioma of infancy with topical imiquimod 5\%: a report of 3 cases. Ear Nose Throat J. 2010;89(3):20229466-20229466.

[4] Abbeele TVD, Triglia JM, Lescanne E, Roger G, Nicollas R, Ployet MJ, et al. Surgical Removal of Subglottic Hemangiomas in Children. The Laryngoscope. 1999;109(8):12811286. Available from: https://dx.doi.org/10.1097/00005537199908000-00018.

[5] Welsh O, Olazarán Z, Gómez M, Salas J, Berman B. Treatment of infantile hemangiomas with short-term application of imiquimod 5\% cream. Journal of the American Academy of Dermatology. 2004;51(4):639-642. Available from: https://dx.doi.org/10.1016/j.jaad.2004.04.022.

[6] Frieden IJ, Eichenfield LF, Esterly NB, Geronemus R, Mallory SB. Guidelines of care for hemangiomas of infancy. American Academy of Dermatology Guidelines/Outcomes Committee. J Am Acad Dermatol. 1997;37(4):93442059344205

[7] Sidbury R, Neuschler N, Neuschler E, Sun P, qi Wang X, Puscasiu E, et al. Topically Applied Imiquimod Inhibits Vascular Tumor Growth In Vivo. Journal of Investigative Dermatology. 2003;121(5):1205-1209. Available from: https: //dx.doi.org/10.1046/j.1523-1747.2003.12521.x.

[8] Hu L, Huang HZ, Li X, Lin XX, Li W. Open-label nonrandomized left-right comparison of imiquimod $5 \%$ ointment and timolol maleate $0.5 \%$ eye drops in the treatment of proliferating superficial infantile hemangioma. Dermatology. $2015 ; 230(2): 150-155$.

[9] Mills CM, Marks R. Side effects of topical glucocorticoids. Curr Probl Dermatol. 1993;21:122-153.

[10] Boye E, Jinnin M, Olsen BR. Infantile hemangioma: challenges, new insights, and therapeutic promise. Journal of Craniofacial Surgery. 2009;20:678-84.

[11] Bauland CG, Lüning TH, Smit JM, Zeebregts CJ, Spauwen PHM. Untreated Hemangiomas: Growth Pattern and Residual Lesions. Ovid Technologies (Wolters Kluwer Health); 2011. Available from: https://dx.doi.org/10.1097/prs. 0b013e318208d2ac.

[12] Mao XHW, Yan JY, L J. Topical imiquimod treatment of cutaneous vascular disorders in pediatric patients: clinical evaluation on the efficacy and safety. Journal of Zhejiang University Science B. 2012;13(9):3437372-3437372.

[13] Sethuraman G, Yenamandra V, Gupta V. Management of infantile hemangiomas: Current trends. Journal of Cutaneous and Aesthetic Surgery. 2014;7(2):75-75. Available from: https://dx.doi.org/10.4103/0974-2077.138324.

[14] Blei F, Walter J, Orlow SJ, Marchuk DA. Familial Segregation of Hemangiomas and Vascular Malformations as an Autosomal Dominant Trait. Archives of Dermatology. 1998;134(6):718-740. Available from: https://dx.doi.org/10. 1001/archderm.134.6.718.

[15] Higgins JP, Green S; 2011.

[16] Boon LM, MacDonald DM, Mulliken JB. Complications of Systemic Corticosteroid Therapy for Problematic Hemangioma. Ovid Technologies (Wolters Kluwer Health); 1999. Available from: https://dx.doi.org/10.1097/00006534199911000-00002.

[17] JACOBS AH, WALTON RG. THE INCIDENCE OF BIRTHMARKS IN THE NEONATE. Obstetrical \& Gynecological Survey. 1977;32(2):94-95. Available from: https: //dx.doi.org/10.1097/00006254-197702000-00014.

[18] Frieden IJ. Which hemangiomas to treat-and how? Arch Dermatol. 1997;133(12):9420551-9420551.

[19] Schwarzer G;
[20] Alper JC, Holmes LB. The Incidence and Significance of Birthmarks in a Cohort of 4,641 Newborns. Pediatric Dermatology. 1983;1(1):58-68. Available from: https://dx.doi. org/10.1111/j.1525-1470.1983.tb01093.x.

[21] Guo ZL, Xu G, Gao Q, Li Y, Zhang P, Duan X, et al. Clinical observations on the treatment of infantile hemangiomas with topical imiquimod $5 \%$ cream. Journal of Nanjing Medical University. 2009;23(3):60051-60055.

[22] Munden A, Butschek R, Tom WL, Marshall JS, Poeltler DM, Krohne SE, et al. Prospective study of infantile haemangiomas: incidence, clinical characteristics and association with placental anomalies. British Journal of Dermatology. 2014;170(4):907-913. Available from: https://dx.doi. org/10.1111/bjd.12804.

[23] ttgen KP, Lucky A, Adams D, Pope E, McCuaig C, Powell J, et al. Topical Timolol Maleate Treatment of Infantile Hemangiomas. PEDIATRICS. 2016;138(3):e20160355e20160355. Available from: https://dx.doi.org/10.1542/ peds.2016-0355.

[24] Chinnadurai S, Snyder K, Sathe N, Fonnesbeck C, Morad A, Likis FE. Diagnosis and Management of Infantile Hemangioma. AHRQ Comparative Effectiveness Reviews. 2016;

[25] Health NIO; 2014.

[26] Olsen EA, Cornell RC. Topical clobetasol-17-propionate: Review of its clinical efficacy and safety. Journal of the American Academy of Dermatology. 1986;15(2):246-255. Available from: https://dx.doi.org/10.1016/s0190-9622(86) 70164-3.

[27] Chang J, Most D, Bresnick S, Mehrara B, Steinbrech DS, Reinisch J, et al.. Proliferative Hemangiomas: Analysis of Cytokine Gene Expression and Angiogenesis. Ovid Technologies (Wolters Kluwer Health); 1999. Available from: https://dx.doi.org/10.1097/00006534-199901000-00001.

[28] Leung A, Heal C, Perera M, Pretorius C. A systematic review of patient-related risk factors for catheter-related thrombosis. Journal of Thrombosis and Thrombolysis. 2015;40(3):363-373. Available from: https://dx.doi.org/10. 1007/s11239-015-1175-9.

[29] Ho NTC, Lansang P, Pope E. Topical imiquimod in the treatment of infantile hemangiomas: A retrospective study. Journal of the American Academy of Dermatology. 2007;56(1):63-68. Available from: https://dx.doi.org/ 10.1016/j.jaad.2006.06.011.

[30] Hand JL, Frieden IJ. Vascular birthmarks of infancy: Resolving nosologic confusion. American Journal of Medical Genetics. 2002;108(4):257-264. Available from: https: //dx.doi.org/10.1002/ajmg.10161.

[31] Luu M, Frieden IJ. Haemangioma: clinical course, complications and management. British Journal of Dermatology. 2013;169(1):20-30. Available from: https://dx.doi.org/10. 1111/bjd.12436.

[32] Poetke M, Philipp C, Berlien HP. Flashlamp-Pumped Pulsed Dye Laser for Hemangiomas in Infancy. Archives of Dermatology. 2000;136(5):628-660. Available from: https: //dx.doi.org/10.1001/archderm.136.5.628.

[33] Guo S, Ni N. Topical treatment for capillary hemangioma of the eyelid using beta-blocker solution. Arch Ophthalmol. 2010;128(2):255-261.

[34] Gilbertson EO, Spellman MC, Piacquadio DJ, Mulford MI. Super potent topical corticosteroid use associated with adrenal suppression: Clinical considerations. Journal of the American Academy of Dermatology. 1998;38(2):318-321. Available from: https://dx.doi.org/10.1016/s0190-9622(98) 70573-0.

[35] Chiller KG, Passaro D, Frieden IJ. Hemangiomas of infancy: clinical characteristics, morphologic subtypes, and 
their relationship to race, ethnicity, and sex. Arch Dermatol. 2002;138(12):1567-76.

[36] Kushner BJ. The Treatment of Periorbital Infantile Hemangioma with Intralesional Corticosteroid. Ovid Technologies (Wolters Kluwer Health); 1985. Available from: https://dx.doi.org/10.1097/00006534-198510000-00005.

[37] Egger M, Smith GD, Schneider M, Minder C. Bias in meta-analysis detected by a simple, graphical test. BMJ. 1997;315(7109):629-634. Available from: https://dx.doi. org/10.1136/bmj.315.7109.629.

[38] Peters JL, Sutton AJ, Jones DR, Abrams KR, Rushton L. Comparison of two methods to detect publication bias in meta-analysis. Jama. 2006;295(6):676-80.

[39] Schön M, Schön MP. The antitumoral mode of action of imiquimod and other imidazoquinolines. Curr Med Chem. 2007;14(6):681-688.

[40] Drolet BA, Esterly NB, Frieden IJ. Hemangiomas in Children. New England Journal of Medicine. 1999;341(3):173-181. Available from: https://dx.doi.org/10. 1056/nejm199907153410307.

[41] Metry DW, Hebert AA. Benign Cutaneous Vascular Tumors of Infancy. Archives of Dermatology. 2000;136(7):905-919. Available from: https://dx.doi.org/10.1001/archderm.136.7. 905.

[42] Finn MC, Glowacki J, Mulliken JB. Congenital vascular lesions: Clinical application of a new classification. Journal of Pediatric Surgery. 1983;18(6):894-900. Available from: https://dx.doi.org/10.1016/s0022-3468(83)80043-8.

[43] Mccuaig CCD, Powell J, Belleville J, David C, Rousseau M, Gendron E, et al. Auger, I. A Phase II, Open-Label Study of the Efficacy and Safety of Imiquimod in the Treatment of Superficial and Mixed Infantile Hemangioma. Pediatr Dermatol. 2009;26(2):203-215.

[44] Novoa M, Baselga E, Beltran S, Giraldo L, Shahbaz A, Pardo-Hernandez H. Interventions for infantile haemangiomas of the skin. Cochrane Database Syst Rev. 2018;4(4):29667726-29667726.

[45] Callahan AB, Yoon MK. Infantile hemangiomas: A review. Saudi Journal of Ophthalmology. 2012;26(3):283-291. Available from: https://dx.doi.org/10.1016/j.sjopt.2012.05.004.

[46] Vassar M, Atakpo P, Kash MJ. Manual search approaches used by systematic reviewers in dermatology. Journal of the Medical Library Association : JMLA. 2016;104(4):302304. Available from: https://dx.doi.org/10.3163/1536-5050. 104.4.009.

[47] Jiang CH, Ma X, Chen G, Jin D, Chen Y, Chen H, et al. A prospective self-controlled phase II study of imiquimod $5 \%$ cream in the treatment of infantile hemangioma. Pediatric Dermatology. 2011;28(3):259-66.

[48] Haggstrom AN, Drolet BA, Baselga E, Chamlin SL, Garzon MC, Horii KA, et al. Prospective Study of Infantile Hemangiomas: Clinical Characteristics Predicting Complications and Treatment. PEDIATRICS. 2006;118(3):882-887. Available from: https://dx.doi.org/10.1542/peds.2006-0413.

[49] Liberati A, Altman DG, Tetzlaff J, Mulrow C, Gøtzsche PC, Ioannidis JPA, et al. The PRISMA Statement for Reporting Systematic Reviews and Meta-Analyses of Studies That Evaluate Health Care Interventions: Explanation and Elaboration. PLoS Medicine. 2009;6(7):e1000100-e1000100. Available from: https://dx.doi.org/10.1371/journal.pmed. 1000100.

[50] Qiu Y, Ma G, Lin X, Jin Y, Chen H, Hu X. Treating protruding infantile hemangiomas with topical imiquimod $5 \%$ cream caused severe local reactions and disfiguring scars. Pediatric dermatology. 2013;30(3):342-349.
[51] McCuaig CC, Dubois J, Powell J, Belleville C, David M, Élisabeth Rousseau, et al. A Phase II, Open-Label Study of the Efficacy and Safety of Imiquimod in the Treatment of Superficial and Mixed Infantile Hemangioma. Pediatric Dermatology. 2009;26(2):203-212. Available from: https:// dx.doi.org/10.1111/j.1525-1470.2008.00857.x.

[52] Haggstrom AN, Drolet BA, Baselga E, Chamlin SL, Garzon MC, Horii KA, et al. Prospective Study of Infantile Hemangiomas: Demographic, Prenatal, and Perinatal Characteristics. The Journal of Pediatrics. 2007;150(3):291-294. Available from: https://dx.doi.org/10.1016/j.jpeds.2006.12.003

[53] Seirafi HE, Amirhooshang, Jesri, Shabboo, Gholamali, Fatemeh, et al.; 2012.

[54] Castrén E, Salminen P, Vikkula M, Pitkäranta A, Klockars T. Inheritance Patterns of Infantile Hemangioma. Pediatrics. 2016;138(5):e20161623-e20161623. Available from: https://dx.doi.org/10.1542/peds.2016-1623.

[55] Qiu YM, Lin G, Jin X, Chen Y, Hu H, X. Treating protruding infantile hemangiomas with topical imiquimod $5 \%$ cream caused severe local reactions and disfiguring scars. Pediatric dermatology. 2013;30(3):342-349.

[56] Enjolras O, Mulliken JB. Vascular tumors and vascular malformations (new issues). Adv Dermatol. 1997;13:95511509551150.

[57] Kilcline C, Frieden IJ. Infantile Hemangiomas: How Common Are They? A Systematic Review of the Medical Literature. Pediatric Dermatology. 2008;25(2):168-173. Available from: https://dx.doi.org/10.1111/j.1525-1470.2008.00626.x.

[58] Team RC. R: A Language and Environment for Statistical Computing. Vienna, Austria; 2017. 